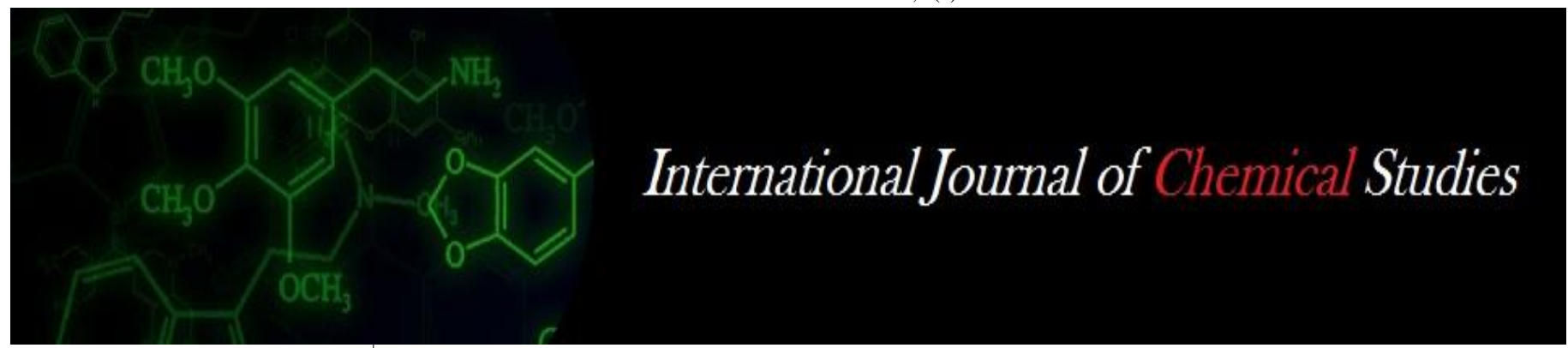

P-ISSN: 2349-8528

E-ISSN: 2321-4902

www.chemijournal.com

IJCS 2021; 9(1): 2867-2871

(C) 2021 IJCS

Received: 01-10-2020

Accepted: 10-12-2020

Kshirsagar Sujit Dadasaheb Food Processing Business Incubation Centre, Indian Institute of Food Processing Technology, MoFPI, GOI, Thanjavur, Tamil Nadu, India

Bhosale Yuvraj Khasherao Food Processing Business Incubation Centre, Indian Institute of Food Processing Technology, MoFPI, GOI, Thanjavur, Tamil Nadu, India

\section{Vincent Hema}

Food Processing Business Incubation Centre, Indian Institute of Food Processing Technology, MoFPI, GOI,

Thanjavur, Tamil Nadu, India

Corresponding Author: Vincent Hema

Food Processing Business Incubation Centre, Indian Institute of Food Processing Technology, MoFPI, GOI, Thanjavur, Tamil Nadu, India

\section{Effect of process parameters on quality of carbonated Kinnow juice}

\author{
Kshirsagar Sujit Dadasaheb, Bhosale Yuvraj Khasherao and Vincent \\ Hema
}

DOI: https://doi.org/10.22271/chemi.2021.v9.i1an.11666

\begin{abstract}
One of the new strategies for enhancing palatability and extending the shelf life of juice without incorporating any synthetic flavours and additives is carbonation. The experiment was designed to study the effect of salt addition in carbonation at different levels of temperature and pressure. Kinnow fruit juice was carbonated at $4{ }^{\circ} \mathrm{C}$ to $8{ }^{\circ} \mathrm{C}$ and pressure of 80 psi to $120 \mathrm{psi}$. TSS and $\mathrm{pH}$ followed inverse relation with carbonation conditions and acidity followed direct relation. Antioxidant activity, total phenols transposes as ascorbic acid and observed highest at 80 psi and $4{ }^{\circ} \mathrm{C}$. Reducing sugar and colour of carbonated kinnow juice remains unaffected at different carbonation conditions. In a nutshell, higher degree of carbonation can be achieved at higher pressure and lower temperature increasing juice acceptability without affecting physical quality. Salt-addition does not have significant effect on its nutritional parameters. Though the nutritional parameters found to be decline, the deviation observed was minimum.
\end{abstract}

Keywords: Carbonation, kinnow, antioxidant activity, total phenol, ascorbic acid

\section{Introduction}

India is the $5^{\text {th }}$ largest producer of citrus fruits. Considering Indian terrain, $10 \%$ of the total land under fruit cultivation is tenanted with citrus crops followed by mango and banana (Mahawar, Jalgaonkar et al. 2019) ${ }^{[7]}$. Kinnow comes under 'Mandarin' group of citrus which was breaded from cross between 'King' (Citrus nobilis) and 'Willow leaf' (Citrus deliciosa) mandarin which is considered to be high quality variety (Mahawar, Jalgaonkar et al. 2019) ${ }^{[7]}$. The mandarin has proved to be high yielding and disease tolerant compared to other citrus fruits grown in India when it was brought to Regional Fruit Research Station, Abhor in 1959 by Punjab Agricultural University. It has been found that it can be cultivated well in Punjab, Himachal Pradesh, Rajasthan, Uttarakhand, Jammu and Kashmir, Uttar Pradesh and Maharashtra states. Unlike other citrus variety, harvesting of kinnow is done based on internal parameters such as TSS (Total soluble solids) is $11{ }^{\circ}$ Brix and acidity is $0.8 \%$. Delay in harvesting can lead to decrease in juice content and the keeping quality of fruit (Mahawar, Jalgaonkar et al. 2019) ${ }^{[7]}$.

The reason for wastage of kinnow and inability of post-harvest processing is lack of proper marketing channels and poor post-harvest management practices. Kinnow cannot be transported in gunny bags unlike other citrus fruits. Continuous and bulk production lead to truckloads in transportation causing damage to fruits. Increase in consumption of unprocessed kinnow escalate the wastage and discarding of low grade fruits. However, direct discarding in open surrounding may lead to environmental damage. This paves an opportunity for kinnow processing of the fruits which can reduce the waste and enhances the economic returns to kinnow producers (Mahawar, Jalgaonkar et al. 2019) ${ }^{[7]}$. The kinnow fruits are processed as drink such as RTS, squash, nectar, fermented products, juice powder, etc. The kinnow juice undergoes process of bittering with time if not processed after extraction which enables the need of immediate processing for it. In general, consumers prefer haze free juices of citrus fruits making it a suitable commodity for carbonation (Mahawar, Jalgaonkar et al. 2019) ${ }^{[7]}$. Carbonation means dissolving the $\mathrm{CO}_{2}$ into water under high pressure. Carbonated drink gives good taste because it shows tingling effect which is the main reason of popularity of carbonated drink along with this it has thrust quenching and refreshing properties 
(Solanke, Sontakke et al. 2017) ${ }^{[13]}$. Carbonated drinks are generally acidic in nature consists of $\mathrm{pH} 2.5$ to 4 and $\mathrm{CO}_{2}$ volume 1.5 to $4 \%$. Low $\mathrm{pH}$ attained by acidulants inhibits the growth of microbes which further is assisted by preservative action of $\mathrm{CO}_{2}$ making carbonated drinks self-stable (Azeredo, Alvarenga et al. 2016) ${ }^{[3]}$. Moreover, conventional carbonated drinks shows various health issues such as increased blood sugar, obesity and tooth erosion (Rajeev, Lewis et al. 2020) [10].

Traditional and commercial carbonated beverages are prepared from syrup or cola type which lacks the nutritional profile. Though the fruit juices are good source of various macro and micro nutrients, they lack in self-stability. Inclusion of fruit juices in carbonated drinks at commercial level is very limited and has lot of scope to become a major part, commercially. Carbonation of fruit juice not only imparts characteristics colour, flavour, taste, aroma but also allows to work without artificial colour and flavours (Verma 2018) ${ }^{[15]}$.

In present work, a comparative study was conducted between carbonated kinnow drink with salt and without salt addition at different temperatures and pressure levels. The physiochemical and nutritional properties were considered to decide the optimized temperature and pressure suitable for carbonation of kinnow fruit juice.

\section{Materials and Methods \\ 2.1 Raw materials}

Kinnow fruits used for the experiment were procured from orchard in Bhatinda, Punjab and medium size fully matured fruits were selected for the experiments. Remaining materials were purchased from Thanjavur Consumer Co-operative Warehouse (Thanjavur, Tamil Nadu, India) and food grade additives viz. acid regulators and preservative were purchased from Himedia (Himedia, Nashik, India).

\subsection{Preparation of carbonated kinnow fruit drink}

The kinnow fruits were sorted based on maturity. The selected fruits were washed using bubble washer and juice was extracted by using citrus-juice extractor (Accelor Food Tech., Coimbatore, India) from kinnow fruits. The extracted juice was filtered through plate and frame filter press. The fruit juice was maintained at, total soluble solid $15 \%$, acidity $1.5 \%$ and preservative $60 \mathrm{ppm}$ and further used for preparation of kinnow fruit nectar. The standardised dilution factor K50 (kinnow: water, 50:50) was considered for further experiment of carbonation. The kinnow fruit juice dilution factor of $\mathrm{K} 50$ was prepared and subjected to pasteurization at $115 \pm 0.5{ }^{\circ} \mathrm{C}$ for $2 \mathrm{sec}$ seconds followed by instant cooling at $25 \pm 2{ }^{\circ} \mathrm{C}$ and stored at refrigeration condition at $4{ }^{\circ} \mathrm{C}$ (Eagerman and Rouse 1976) ${ }^{[6]}$.

After cooling, the pasteurized kinnow fruit nectar subjected to carbonation and the detailed flow chart is given in figure 1. The experiment was performed to compare the effect of temperature and pressure on kinnow juice with salt and without salt. The developed formula was chilled and carbonation was done at $4{ }^{\circ} \mathrm{C}, 6{ }^{\circ} \mathrm{C}$ and $8{ }^{\circ} \mathrm{C}$ temperature in the pressure range of $80 \mathrm{psi}, 90 \mathrm{psi}, 100 \mathrm{psi}, 110 \mathrm{psi}$ and 120 psi by using carbonation unit (Spectra Plast India, Coimbatore, India). Carbonation was carried with addition of $0.5 \%$ salt and. The prepared kinnow drinks were filled in $250 \mathrm{ml}$ bottles and sealed tightly by using capping machine and it was stored at refrigeration condition at $4{ }^{\circ} \mathrm{C}$ for further evaluation of physicochemical and phytochemical properties.

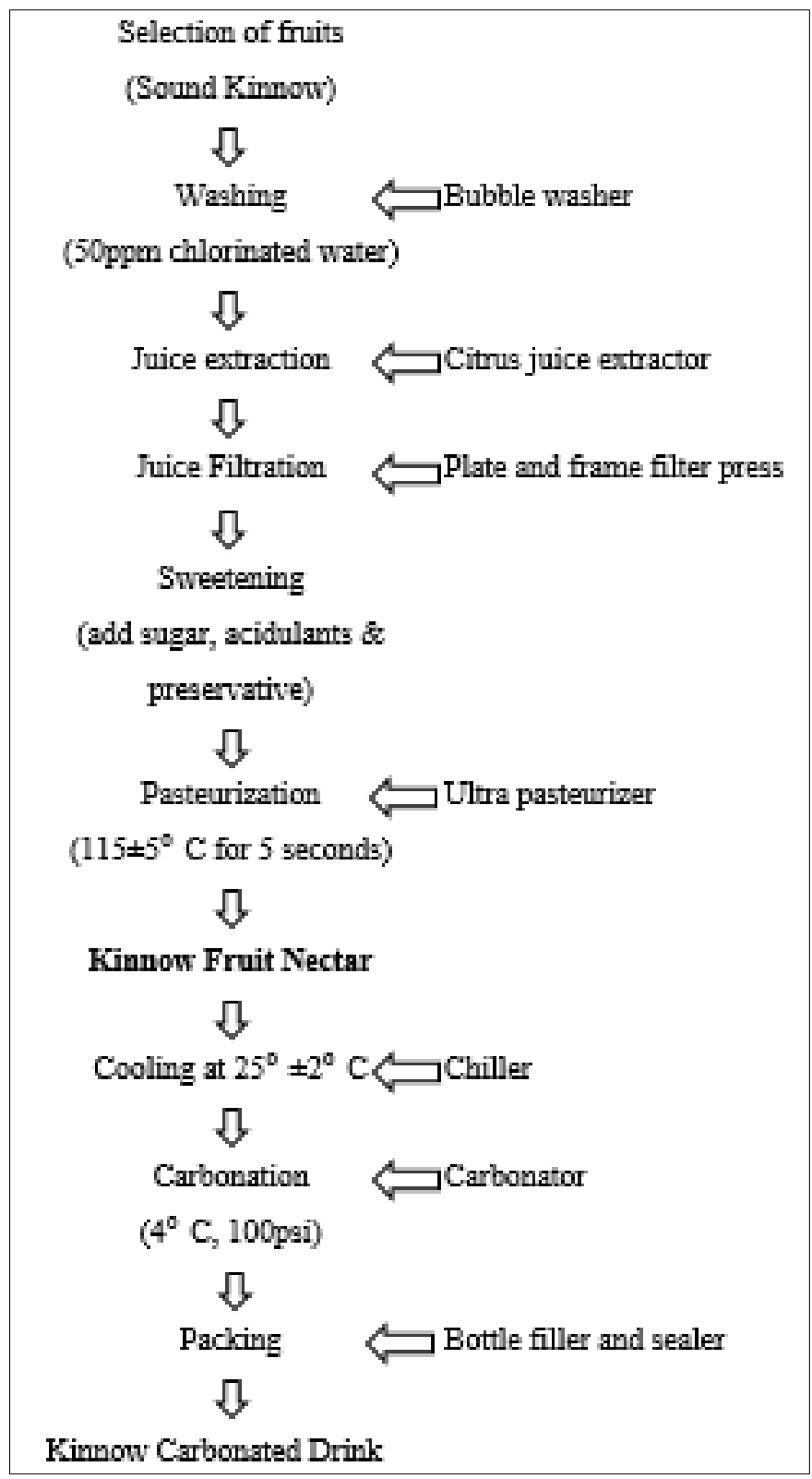

Fig 1: Flow Sheet for the Processing of Carbonated Kinnow Fruit Drink

\subsection{Quality analysis}

\subsubsection{Total soluble solids}

Total Soluble Solids (TSS) was measured using the digital refractometer (ATAGO PAL-LOOP, Fukaya, Japan). A one or two drops of carbonated kinnow drink was placed on digital refract meter. The TSS value was expressed as ${ }^{\circ}$ Brix (Mohapatra, Yuvraj et al. 2016) ${ }^{[9]}$.

\subsection{2 pH}

The $\mathrm{pH}$ of the fresh fruit juice was determined by using digital $\mathrm{pH}$ meter (pH Tutor, Eutech Instruments, Singapore). The $\mathrm{pH}$ meter was calibrated with commercial buffer solutions at $\mathrm{pH}$ 9.0, 7.0 and 4.0 before measurement. About $10 \mathrm{ml}$ sample was taken in glass container and $\mathrm{pH}$ electrode was inserted the $\mathrm{pH}$ value was recorded after stabilization (Agarkar, Aggarwal et al. 2019) ${ }^{[1]}$.

\subsubsection{Titrable acidity}

The $10 \mathrm{ml}$ sample of kinnow juice was diluted with water at ratio 1:10. From that $25 \mathrm{ml}$ of solution was taken in beaker 
and 2 to 3 drops of phenolphthalein indicator was added and titrated against $0.1 \mathrm{~N} \mathrm{NaOH}$ till color changed to pink. Then the values were noted and acidity was determined by the following formula (Ranganna 1986) ${ }^{[11]}$.

Titrable acidity $(\%)=\frac{\text { Titratevalue } \times \text { acidfactor } \times 100}{\text { volume of aliquot }} \quad \ldots 1$

\subsubsection{Ascorbic acid}

Ascorbic acid was determined by titrating the sample against 2-6, dichlorophenol indophenol with sodium carbonate in which sample preparation include $5 \mathrm{ml}$ of sample with $100 \mathrm{ml}$ $4 \%$ oxalic acid further centrifuged. $5 \mathrm{ml}$ of supernatant was collected and mixed with $10 \mathrm{ml}$ of $4 \%$ oxalic acid and the titrated against dye. Amount of vitamin $\mathrm{C}$ was calculated by equation 3.

Amount of ascorbic acid mg/100ml sample $=\frac{0.5 \mathrm{mg}}{V_{1} \mathrm{ml}} \times \frac{V_{2}}{5 \mathrm{ml}} \times \frac{100 \mathrm{ml}}{\text { Sample volume }} \times 100 \ldots 2$

\subsubsection{Antioxidants}

Total antioxidant activity was determined by 2, 2' diphenylpicrylhydrazyl (DPPH) assay reported by (Zubia and Dizon 2019) and (Darsana, Bhosale Yuvraj et al. 2016) with slight modification. $300 \mu \mathrm{l}$ of sample was taken and added with $4 \mathrm{ml}$ of methanolic solution of DPPH with $0.004 \%$ concentration. The mixed solution was kept in dark for half an hour and absorbance was recorded at $517 \mathrm{~nm}$ against the reagent blank. Results were expressed in terms of the percent inhibition of free radicals and it was calculated by following equation:

$\%$ Inhibition $=\frac{\left(A_{\text {blank }}-A_{\text {sample }}\right)}{A_{\text {blank }}} \times 100$

Where A blank was absorbance of DPPH radical in methanol and A sample was absorbance of DPPH radical mixed with sample.

\subsubsection{Total phenol content}

By using Folin-Ciocalteu method, the total phenol content of sample was determined as reported by (Theagarajan, Malur Narayanaswamy et al. 2019) [14] with slight changes on procedure. $300 \mu \mathrm{l}$ of juice was mixed with $1 \mathrm{ml}$ of FolinCiocalteu reagent prepared 1:10 with distilled water and it was mixed vigorously. $1 \mathrm{ml}$ of $10 \% \mathrm{Na}_{2} \mathrm{CO}_{3}$ was added and final volume was made up to $5 \mathrm{ml}$ with distilled water. The dispersion was left for half an hour at room temperature and absorbance was measured at $765 \mathrm{~nm}$ using UV-Vis Spectrophotometer (UV-1800, Shimadzu, Japan). The total phenol content was expressed as $\mathrm{mg}$ gallic acid equivalents per $\mathrm{ml}$ of juice.

\section{Result and Discussion \\ 3.1 Total soluble solids}

Observational data shows very negligible changes in TSS after carbonation. There is a decrease in TSS with the rise in pressure at constant temperature, (Aggarwal, Bajaj et al. 1992) ${ }^{[2]}$ recorded that TSS remained the same with negligible changes in carbonated peach nectar. Kinnow juice carbonation has no major effect on the TSS of juice. Maximum TSS $8.15 \pm 0.07^{\circ}$ Brix observed at 80 psi pressure and $4^{\circ} \mathrm{C}$ temperature in sample containing salt and without salt. Minimum value of TSS $7.65 \pm 0.07^{\circ}$ Brix was observed for sample with salt at $120 \mathrm{psi}$ and $8^{\circ} \mathrm{C}$ and found lowest for without salt sample $7.55 \pm 0.07^{\circ} \mathrm{Brix}$ at same processing conditions. TSS values for sample with salt and without salt found statistically non-significant. During thermal processing, complex polymeric carbohydrates break down into simple soluble sugars and this may be the explanation why total soluble solids in pasteurized juice kinnow juice increase (Margean, Lupu et al. 2020) ${ }^{[8]}$. Following graph shows the decrease in TSS-

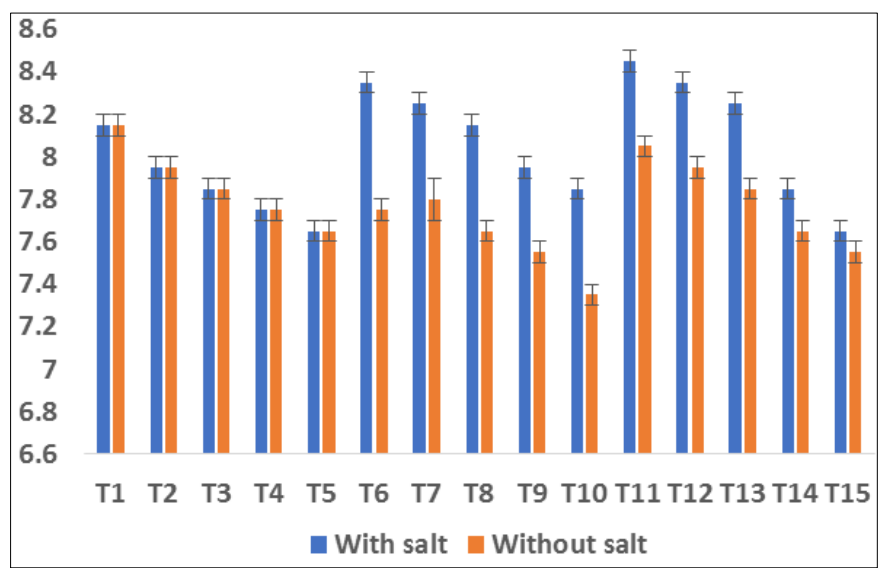

T1-80psi \& $4{ }^{\circ} \mathrm{C}$, T2-90psi \& $4{ }^{\circ} \mathrm{C}$, T3-100psi \& $4{ }^{\circ} \mathrm{C}$, T4-110psi \& $4{ }^{\circ} \mathrm{C}$, T5-120psi \& $4{ }^{\circ} \mathrm{C}$, T6-80psi \& $6{ }^{\circ} \mathrm{C}$, T7-90psi \& $6{ }^{\circ} \mathrm{C}$, T8100 psi \& $6{ }^{\circ} \mathrm{C}$, T9-110psi \& $6{ }^{\circ} \mathrm{C}$, T10-120psi \& $6{ }^{\circ} \mathrm{C}, \mathrm{T} 11-80 \mathrm{psi} \&$ $8{ }^{\circ} \mathrm{C}$, T12-90psi \& $8{ }^{\circ} \mathrm{C}$, T13-100psi \& $8{ }^{\circ} \mathrm{C}$, T14-110psi \& $8{ }^{\circ} \mathrm{C}$, T15-120psi \& $8{ }^{\circ} \mathrm{C}$

Fig 2: Effect of carbonation temperature and pressure on TSS

\section{$3.2 \mathrm{pH}$ and acidity}

Increased pressure induces reduced $\mathrm{pH}$ at each carbonation temperature, which is not significant, although with the rise in pressure, acidity shows significant changes. Effective carbonation is caused by increased pressure and shows more acidity supported by (SILER, MORRIS et al. 1993) ${ }^{[12]}$ as they stated that carbonated juices produce higher titratable acidity and this rise in acidity was defined during titration with dissociation of carbonic acid. Maximum $\mathrm{pH}$ was observed at $80 \mathrm{psi}$ pressure and $4^{\circ} \mathrm{C}$ temperature. Sample with salt had 4.015 \pm 0.02 and without salt sample had 4.01 \pm 0.01 which were non-significant. Minimum $\mathrm{pH}$ value for with salt sample was $3.95 \pm 0.01$ and without salt sample contains $3.945 \pm 0.007$ which was found non-significant at 120 psi pressure and $8{ }^{\circ} \mathrm{C}$ temperature. Vice-versa Acidity found lowest at 80 psi pressure and $4{ }^{\circ} \mathrm{C}$ temperature. For sample with salt, it was $0.485 \pm 0.007 \%$ and for without salt sample it was $0.475 \pm 0.007 \%$. Highest acidity was found at $120 \mathrm{psi}$ pressure and $8{ }^{\circ} \mathrm{C}$ temperature. For sample with salt it was $0.56 \pm 0.007 \%$ and sample without salt had $0.57 \pm 0.01 \%$ which were non-significant. $\mathrm{pH}$ and acidity of drink was represented graphically below- 


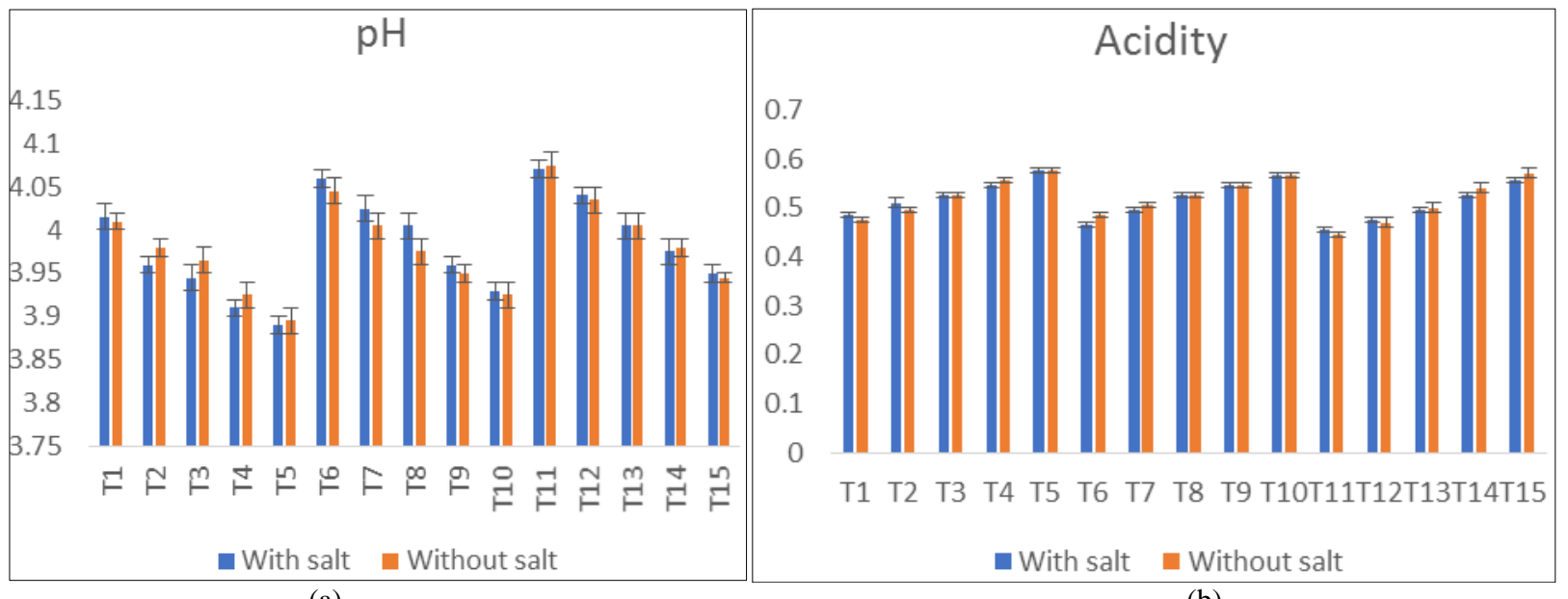

(a)

(b)

Fig 3: Effect of carbonation temperature and pressure on $\mathrm{pH}$ and Acidity

\subsection{Ascorbic acid}

As the carbonation pressure rises, the vitamin $\mathrm{C}$ content of kinnow juice was observed to decrease with minor variance. The headspace inside the bottle is packed with $\mathrm{CO} 2$, which inhibits ascorbic acid aerobic oxidation and maintains the stability of vitamin C (Zhao, Qin et al. 2018) ${ }^{[16]}$. Maximum retention of ascorbic acid was observed at 80 psi pressure and $4{ }^{\circ} \mathrm{C}$ temperature for sample with salt $34.63 \pm 1.16 \mathrm{mg} / 100 \mathrm{ml}$ and in sample without salt it was observed at 31.29 \pm 1.64 $\mathrm{mg} / 100 \mathrm{ml}$ which are significantly different. Ascorbic acid found lowest during carbonation at 120 psi pressure and $8{ }^{\circ} \mathrm{C}$ temperature, for sample with salt it was $24.48 \pm 0.95 \mathrm{mg} / 100 \mathrm{ml}$ and sample without salt it was found to be at $24.44 \pm 1.79$ $\mathrm{mg} / 100 \mathrm{ml}$. Change in ascorbic acid was represented graphically below-

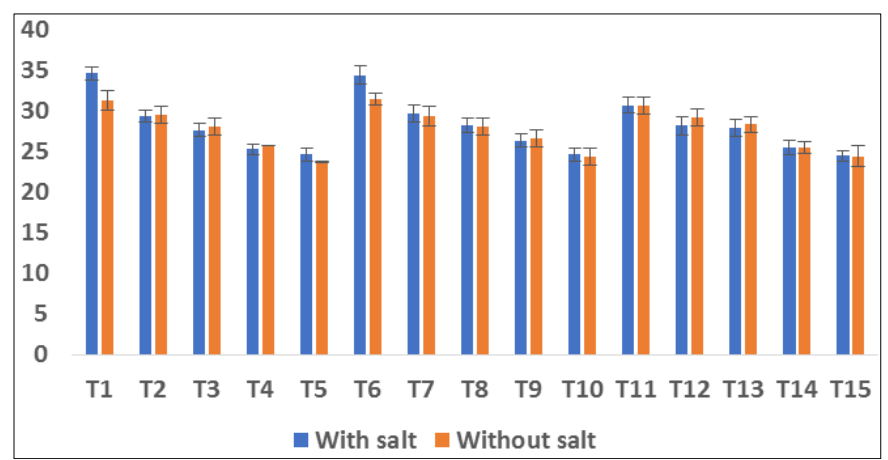

Fig 4: Effect of carbonation temperature and pressure on Ascorbic acid

\subsection{Antioxidants}

With the rise in pressure for carbonation, antioxidants appear to be decreased in the experiment. Oxidation of some bioactive ingredients such as vitamin $\mathrm{C}$, carotenoids and phenolic compounds with the help of activation of certain enzymes, including peroxidase, polyphenol oxidase, may clarify this loss of antioxidant function after carbonation (De Ancos, Rodrigo et al. 2020) ${ }^{[5]}$. Maximum antioxidant activity was found at 80 psi pressure and $4{ }^{\circ} \mathrm{C}$ temperature. Sample with salt had $55.15 \pm 0.42 \%$ activity while sample without salt had $58.7 \pm 1.06 \%$ activity which is significantly different. Minimum activity was observed at 120 psi pressure and $8{ }^{\circ} \mathrm{C}$ temperature. For sample with salt it was at $43.3 \pm 1.37 \%$ and for sample without salt it was observed at $40.65 \pm 1.42 \%$ activity. Decrease with pressure in antioxidant activity was graphically represented below-

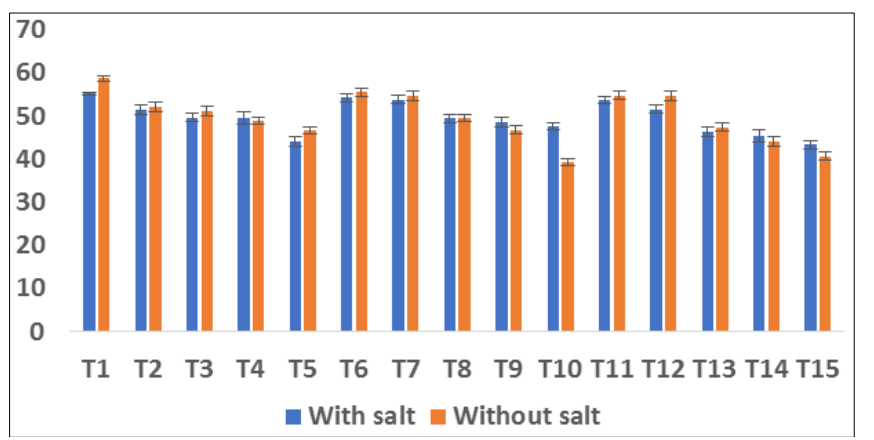

Fig 5: Effect of carbonation temperature and pressure on Antioxidants

\subsection{Total Phenol}

The dissolved $\mathrm{CO} 2$ can have an effect on enzymes because it helps to shift the ionic equilibrium and affect the activity under high pressure. Bubbling refers to enzyme inactivation during carbonation and de pressurization. These enzymes are responsible for reaction that cause the depletion of phenols (Zhao, Qin et al. 2018) ${ }^{[16]}$. Maximum retention of total phenol was observed at 80 psi pressure and $4{ }^{\circ} \mathrm{C}$ temperature for sample with salt $1.675 \pm 0.07 \mathrm{mg} / 100 \mathrm{ml}$ and in sample without salt it was observed at $1.67 \pm 0.01 \mathrm{mg} / 100 \mathrm{ml}$ which are not significantly different. Total phenol found lowest during carbonation at 120 psi pressure and $8{ }^{\circ} \mathrm{C}$ temperature, for sample with salt it was $1.47 \pm 0.01 \mathrm{mg} / 100 \mathrm{ml}$ and sample without salt it was found to be at $1.43 \pm 0.02 \mathrm{mg} / 100 \mathrm{ml}$.

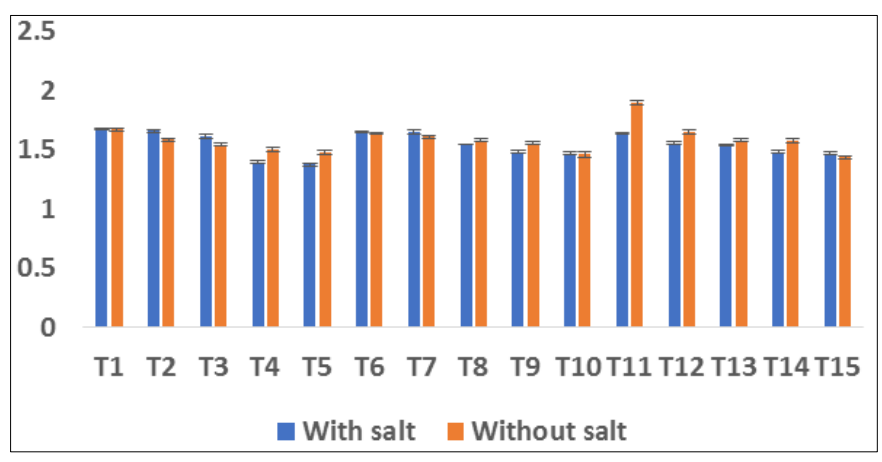

Fig 6: Effect of carbonation temperature and pressure on Total phenols

\section{Conclusion}

Carbonation of kinnow juice enhances the organoleptic properties with its mouth feel, tingling effect, imposes 
refreshing quality with healthy natural taste of fruit. The present study describes that the addition of salt into drink does not have significant effect on its palatability as well as its physicochemical and phytochemical parameters. After carbonation phytochemical properties showed good retention. Carbonation of fruits has further potential application and can be major part for replacing sugar based soft drink. Kinnow is the underutilized fruit, which has greater health benefits and nutrient-rich benefits. In this section, further scope is enriched carbonated kinnow drink with a variety of flavours to enhance consumer preference, which leads to increased demand for kinnow fruit to support farmers and processors 'economic status.

\section{References}

1. Agarkar BS et al. Preparation of carbonated sugarcane juice beverages blended with fruit juices. 2019;56(1):124-133.

2. Aggarwal $\mathrm{P}$ et al. Comparative studies on the suitability of Shan-i-Punjab and Flordasun peach varieties for processing 1992;8:77-80.

3. Azeredo DR et al. An overview of microorganisms and factors contributing for the microbial stability of carbonated soft drinks 2016;82:136-144.

4. Darsana $\mathrm{K}$ et al. effect of aril browning on Physichochemical properties of pomegranate 2016;5:1116-1126.

5. De Ancos B et al. Effect of high-pressure processing applied as pretreatment on carotenoids, flavonoids and vitamin $\mathrm{C}$ in juice of the sweet oranges' Navel'and the red-fleshed'Cara Cara' 2020;132:109105.

6. Eagerman B, Rouse AJJoFS. Heat inactivation temperature-time relationships for pectinesterase inactivation in citrus juices 1976;41(6):1396-1397.

7. Mahawar MK et al. Post-harvest processing and valorization of Kinnow mandarin (Citrus reticulate L.): A review 2019, 1-17.

8. Margean A et al. An overview of effects induced by pasteurization and high-power ultrasound treatment on the quality of red grape juice 2020;25(7):1669.

9. Mohapatra A et al. Physicochemical changes during ripening of red banana 2016;5(3):1340-1348.

10. Rajeev $\mathrm{G}$ et al. A time based objective evaluation of the erosive effects of various beverages on enamel and cementum of deciduous and permanent teeth 2020;12(1):e1.

11. Ranganna S. Handbook of analysis and quality control for fruit and vegetable products, Tata McGraw-Hill Education 1986.

12. Siler A et al. Quality effects of carbonation and ethyl maltol on venus and concord grape juices and their grapeapple blends 1993;44(3):320-326.

13. Solanke ND et al. Study on effect of carbonation on the properties of fruit juices 2017;4:2426-2432.

14. Theagarajan $\mathrm{R}$ et al. Valorisation of grape pomace (cv. Muscat) for development of functional cookies 2019;54(4):1299-1305.

15. Verma SJIJCMAS. Fruit Based Carbonated Soft Drinks for Nutritional Security and Value Chain DevelopmentA Review 2018;7(11):3084-3095.

16. Zhao $\mathrm{L}$ et al. Novel application of $\mathrm{CO} 2$-assisted high pressure processing in cucumber juice and apple juice 20181;96:491-498.

17. Zubia C, Dizon EJIFRJ. Physico-chemical, antioxidant and sensory properties of artificially-carbonated fruit wine blends 2019;26(1):217-224. 